Journalof Science

and Engineering

Full Paper

\title{
EVAlUASI PEKERJAAN TIMBUNAN PADA TANAH RAWA (LUNAK) DI PROYEK PLTMG KASTELA
}

\author{
Jamalun Togubu, Djulisha S. Hakim ${ }^{\text {** }}$ \\ aUniversitas Khairun, Ternate, Indonesia \\ bUniversitas Khairun, Ternate, Indonesia
}

Article history

Received

30 September 2021

Received in revised form

2 Oktober 2021

Accepted

20 Oktober 2021

*Corresponding author jamaluntogubu@unkhair.ac.id

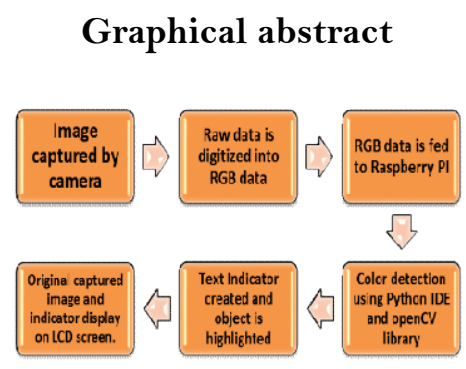

\begin{abstract}
Swamp soil (soft soil) is a natural puddle of water that occurs continuously or seasonally due to obstructed natural drainage and has special physical, chemical and biological characteristics. The purpose of this research is to find out how much the strength of the embankment can increase the technical value of the swamp land. Testing the physical properties of the soil and testing the mechanical properties of the soil in which the marsh soil test is added with variations of $1 \%$, $1.05 \%, 1.1 \%, 1.15 \%$ and $2.00 \%$ has a soil frictional strength of $2.33^{\circ}, 6,40^{\circ} 10,41^{\circ}, 1,1^{\circ}, 1,15^{\circ}$ $2.00^{\circ}$ while the free compressive strength on swamp soil with various variations of $1 \%, 1.05 \%$, $1.1 \%, 1.15 \%$, and $2.0 \%$ has a free compressive strength value of $0.0122 \mathrm{~kg} / \mathrm{cm}^{2}, 0.0124 \mathrm{~kg} / \mathrm{cm}^{2}$, $0.0128 \mathrm{~kg} / \mathrm{cm}^{2}, 0.0136 \mathrm{~kg} / \mathrm{cm}^{2}$ and $0.0702 \mathrm{~kg} / \mathrm{cm}^{2}$. The experimental results of the addition of variations in frictional strength show that the strength of the embankment can increase the technical value of the swamp soil.
\end{abstract}

Keywords: Swamp soil, strength value of Swamp soil, unconfining compression strength

\begin{abstract}
Abstrak
Tanah Rawa (tanah lunak) adalah lahan genangan air secara alamiah yang terjadi terus menerus atau musiman akibat drainase alamiah yang terhambat serta mempunyai ciri khusus secara fisik, kimia dan biologis, Tanah rawa merupakan jenis tanah yang memiliki daya dukung yang rendah. Tujuan dari penelitian ini adalah untuk mengetahui seberapa besar kekuatan Timbunan dapat meningkatkan nilai teknis Tanah Rawa. Pengujian sifat fisik tanah dan pengujian sifat mekanis tanah di mana pada pengujian tanah rawa di tambahkan variasi $1 \%, 1,05 \%, 1,1 \%, 1,15 \%$ dan 2,00 $\%$ memiliki kuat gesek tanah $2,33^{\circ}, 6,40^{\circ} 10,41^{\circ}, 1,1^{\circ}, 1,15^{\circ}, 2,00^{\circ}$ sedangkan kuat tekan bebas pada tanah rawa dengan berbagai variasi $1 \%, 1,05 \%, 1,1 \%, 1,15 \%$, dan $2,0 \%$ memiliki nilai kuat tekan bebas $0,0122 \mathrm{~kg} / \mathrm{cm}^{2}, 0,0124 \mathrm{~kg} / \mathrm{cm}^{2}, 0,0128 \mathrm{~kg} / \mathrm{cm}^{2}, 0,0136 \mathrm{~kg} / \mathrm{cm}^{2}$ dan $0,0702 \mathrm{~kg} / \mathrm{cm}^{2}$. Hasil percobaan kuat gesek penambahan variasi menunjukan bahwa besar kekuatan timbunan dapat meningkatkan nilai teknis tanah rawa.
\end{abstract}

Kata kunci: Tanah Rawa,Nilai Teknis Tanah Rawa, Kuat Tekan Bebas

(C) 2018 Penerbit Fakultas Teknik Unkhair. All rights reserved

\subsection{PENDAHULUAN}

Tanah selalu mempunyai peranan yang penting pada pekerjaan teknik sipil, Banyak pembangunan seperti gedung dilakukan di atas tanah yang memiliki kualitas yang kurang baik, seperti tanah rawa. Rawa adalah lahan genangan air secara alamiah yang terjadi terus menerus atau musiman akibat drainase alamiah yang terhambat serta mempunyai ciri khusus secara fisik, kimia dan biologis [1]. Pengertian lahan rawa adalah wadah air beserta air dan daya air yang terkandung di dalamnya, tergenang secara terus menerus atau musiman, 
terbentuk secara alami di lahan yang relatif datar atau cekung dengan endapan mineral atau gambut, dan ditumbuhi vegetasi, yang merupakan suatu ekosistem[2].

Berdasarkan uraian di atas maka dapat di nyatakan bahwa lahan rawa adalah daerah dimana muka air di tanah berada dekat atau di atas permukaan, tanah yang jenuh air untuk jangka waktu tertentu sehingga kelebihan air dan mengakibatkan kadar oksigen tanah jadi terbatas, hal ini merupakan penentu utama jenis vegetasi dan proses perkembangan tanah. Istilah "swamp" atau rawa digunakan untuk menyatakan wilayah atau area yang secara permanen selalu jenuh air, permukaan air tanahnya dangkal, atau tergenang air dangkal hampir sepanjang tahun, air yang cenderung tidak bergerak atau tidak mengalir (stagnant).

Tanah rawa merupakan jenis tanah yang memiliki daya dukung yang rendah. Hal ini menuntut perlu adanya stabilisasi atau perbaikan tanah pada kondisi jenis tanah tersebut [3]. Salah satu cara untuk meminimalisir dampak yang diakibatkan oleh kondisi tanah rawa tersebut adalah dengan cara penimbunan. Pada proyek PLTMG kastela, beroperasi sejak tahun 2017 melakukan perluasan lahan yang berlokasi di sisi utara, untuk Proyek pembangunan GARDU INDUK, proyek tersebut berada di daerah tanah rawa (lunak), sehingga di lakukan penimbunan pada daerah tersebut, maka dari itu penulis melakukan "Evaluasi Pekerjaan Timbunan Pada Tanah Rawa (Lunak) Di Proyek PLTMG Kastela”.

\subsection{METODE PENELITIAN}

Jenis penelitian yang digunakan ialah penelitian kuantitatif. Penelitian Kuantitatif merupakan suatu pendekatan penelitian dimana peneliti akan bekerja dengan angka-angka sebagai perwujudan gejala yang diamati. Dalam pendekatan kuantitatif, penulis biasanya menggunakan metode-metode statistik dalam pembahasan dan analisa data. Dalam kelompok penelitian kuantitatif terdapat beberapa jenis penelitian yaitu penelitian survei, penelitian eksperimen serta analisis data.

A. Pengujian sifat fisik pada tanah lunak

1. Pengujian kadar airbertujuan untuk mengetahui kadar air tanah pada sampel tanah, yaitu perbandingan antara berat air yang terkandung dalam butiran tanah dengan butiran tanah kering yang dinyatakan dalam persen.

2. Pengujian berat Volumebertujuan untuk menentukan berat volume tanah dengan keadaan tanah asli (undirstubed sampel) yaitu perbandingan berat tanah.

3. Pengujian berat jenisbertujuan untuk menentukan berat jenis tanah yang lolos saringan no 200 dengan menggunakan picnometer.

4. Pengujian atterberg

Pada pengujian batas atterberg bertujuan untuk menentukan kadar air suatu jenis tanah pada batasan antara keadaan plastis dan keadaan cair sesuai ketentuan di tentukan oleh atterberg.

5. Pengujian analisa saringan

Pengujian analisa saringan bertujuan untuk mengetahui presentase ukuran butiran tanah dan sususnan butiran tanah gradasi dari suatu jenis tanah yang tertahan di saringan nomor 200.

B. Pengujian sifat mekanis pada tanah lunak

1. Pengujian Kuat Geseradalah gaya perlawanan yang dilakukan oleh butir-butir tanah terhadap desakan atau tarikan. Dengan dasar pengertian ini, bila tanah mengalami pembebanan akan ditahan oleh (Hardiyatmo, 2002):

1. Kohesi tanah yang bergantung pada jenis tanah dan kepadatannya, tetapi tidak tergantung dari tegangan normal yang bekerja pada bidang geser.

2. Gesekan antara butir-butir tanah yang besarnya berbanding lurus dengan tegangan normal pada bidang gesernya.

2. Pengujian Tekan Bebas atau kekuatan tekan bebas adalah besarnya beban aksial persatuan luas pada saat benda uji mengalami keruntuhan atau pada saat regangan aksial mencapai $20 \%$. Percobaan kuat tekan bebas di laboratorium dilakukan pada sampel tanah dalam keadaan asli maupun buatan (remoulded).

\subsection{HASIL DAN PEMBAHASAN}

\subsection{Pengujian Propertis Tanah}

Untuk pengujian sifat fisis tanah Kelurahan Kastela terdiri dari pengujian kadar air, berat isi, analisa saringan, serta berat jenis sebagai berikut : 
Tabel 3.1 Hasil Analisa sifat fisis Tanah Rawa (Lunak) Kelurahan Kastela

\begin{tabular}{|c|c|c|c|c|c|}
\hline \multirow[b]{2}{*}{ NO } & \multirow{2}{*}{\multicolumn{2}{|c|}{$\begin{array}{c}\text { Macam Pemeriksaan } \\
\text { Tanah } \\
\end{array}$}} & \multicolumn{2}{|c|}{ Hasil Pengujian } & \multirow{2}{*}{$\begin{array}{l}\text { Nilai } \\
\text { Rata } \\
\text { - rata }\end{array}$} \\
\hline & & & Titik 1 & Titik 2 & \\
\hline 1 & & Kadar Air & 17,35 & 17,02 & 8,675 \\
\hline \multirow[b]{3}{*}{2} & \multicolumn{2}{|r|}{ Core Cutter } & & & \\
\hline & A & $\begin{array}{l}\text { Berat Isi Basah } \\
(\mathrm{gr} / \mathrm{cm})\end{array}$ & 187 & 201,2 & 194,1 \\
\hline & $\mathrm{B}$ & $\begin{array}{c}\text { Berat Isi } \\
\text { Kering }(\mathrm{gr} / \mathrm{cm})\end{array}$ & 79,8 & 92,2 & 86 \\
\hline \multirow{4}{*}{3} & \multicolumn{2}{|r|}{ Analisa Saringan } & & & \\
\hline & A & Krikil (\%) & 0,5 & 0,5 & 0,5 \\
\hline & B & Pasir (\%) & 83,4 & 83,5 & 83,45 \\
\hline & C & Lanau/lempung & 16,12 & 16,01 & 16,065 \\
\hline 4 & & Berat jenis (GS) & 2,2 & 2,3 & 2,25 \\
\hline \multirow{4}{*}{5} & \multicolumn{2}{|r|}{ Atterberg } & & & \\
\hline & A & LL (\%) & 46,24 & 47,01 & 46,625 \\
\hline & B & PL (\%) & 42,11 & 44,74 & 43,425 \\
\hline & C & $\mathrm{IP}(\%)$ & 4,13 & 2,27 & 3,2 \\
\hline
\end{tabular}

Hasil pemeriksaan sifat fisik tanah (tanah rawa) yang berasal dari Kelurahan Kastela kecamatan Ternate Selatan yaitu pemeriksaan Kadar Air, Berat Volume, Analisa saringan, Berat Jenis, dan Atterberg.

\section{a. Kadar Air}

Hasil pemeriksaan kadar air untuk tanah rawa pada titik I di peroleh nilai sebesar 17,35\%, dan titik II $17,02 \%$. Hal ini menunjukkan bahwa tidak semua tanah mempunyai kemampuan memegang air yang sama dikarenakan kemampuan memegang air tanah pada setiap jenis tanah ditentukan oleh agregasi tanah, yang sangat tergantung kepada tekstur tanah dan kandungan bahan organik dalam tanah. Sehingga untuk tanah-tanah bertekstur kasar (pasir) mempunyai kemampuan memegang air yang lebih rendah di bandingkan dengan tanah yang bertekstur halus (liat).

\section{b. Berat Volume}

Hasil pemeriksaan berat volume terbagi atas dua yaitu berat volume tanah basah dan berat volume tanah kering, dimana nilai berat volume tanah basah untuk ttik I di peroleh sebesar $187 \mathrm{gr} / \mathrm{cm}$, dan titik II sebesar $201,2 \mathrm{~kg} / \mathrm{cm}$. Hal ini menunujukkan bahwa semakin tinggi penambahan jumlah kadar air, maka berat tanah basah akan berkurang karena pertambahan air tersebut akan memeperkecil konsentrasi partikel-partikel padat tanah persatuan volume.

Sedangkan nilai berat volume tanah kering untuk titik I diperoleh sebesar $79,8 \mathrm{~kg} / \mathrm{cm}$, titik II sebesr 92,9 $\mathrm{kg} / \mathrm{cm}$. Hal ini menunjukkan bahwa semakin sedikit kadar air yang terkandung di dalam tanah maka semakin besar berat volume kering tanah.

\section{c. Analisa Saringan}

Hasil pemeriksaan analisa saringan terdiri atas tiga yaitu kerikil, pasir, dan lanau/lempung. Dimana kerikil untuk titik I dan II didapat nilai sebesar 0,5\%. Kemudian pasir untuk titik I di dapat nilai sebesar 83,4\% dan titik II sebesar 83,5\%. Kemudian lanau/lempung untuk titik I di peroleh nilai sebesar 16,12\% dan titik II $16,01 \%$. Hal ini menunjukkan bahwa sampel tanah untuk kerikil yang didapat memiliki persentase tertahan saringan no.4 $(4,75 \mathrm{~mm})$, untuk pasir yang didapat memiliki persentase tertahan saringan no.200 $(0,075 \mathrm{~mm})$, dan lanau/lempung yang di dapat memiliki persentase lolos saringan no.200 (0,075 mm).

\section{d. Berat Jenis}

Hasil pemeriksaan berat jenis untuk titik I yang didapat sebesar 2,2 dan titik II 2,3. Hal ini menunjukan bahwa sampel tanah tersebut termasuk dalam golongan tanah lempung.

\section{e. Batas-batas Atterberg}

Hasil pemeriksaan batas-batas atterberg terbaagi atas tiga yaitu batas plastis (PL), batas cair (LL), dan indeks plastisitas (IP). Dimana nilai batas plastis (PL) untuk titik I yang di dapat sebesar $42,11 \%$ dan titik II di dapat sebesar $44,74 \%$, artinya kadar air yang dibutuhkan oleh tanah tersebut untuk mentranisisi tanah dari keadaan 
semi-padat ke keadaan plastis. Sedangkan nilai batas cair (LL) untuk titik I di dapat sebesar 46,25\% dan titik II sebesar 47,01\%, artinya kadar air yang dibutuhkan oleh tanah asli tersebut untuk mentransisi tanah dari keadaan plastis ke keadaan cair.

Serta nilai Indeks Plastisitas (IP) untuk titik I di dapat sebesar 11,01\% dan II didapat sebesar 11,03\% untuk Tabel 4.1 di atas menunjukan bahwa penguji tanah pada titik 1 tersebut bebutir halus di mana $<35 \%$ tanah yang lolos saringan No. 200 yakni sebanyak 16,12\% dengan batas cair sebesar 46,24\% Serta indeks plastisitas sebesar 4,13 maka menurut AASTHO, Tanah tersebut adalah Termasuk dalam kelompok A-2-7 yang artinya adalah pasir lanau atau lempungan. sedangkan menurut USCS tanah termasuk dalam kelompok CL yaitu lempung anrganik dengan plastis rendah sampai sedang Kemudian tanah pada titik 2 tergolong dalam tanah berbutir halus dimana $<35 \%$ tanah yang lolos saringan No. 200 yakni sebanyak 16,01\%. Dengan batas cair sebesar 47,01\% serta indeks plastisitas sebesar 2,17\%, maka menurut AASTHO, tanah tersebut termasuk dalam kelompok A-2--7 yang artinya adalah pasir lanauan atau lempungan.

\subsection{Pengujian Mekanis Tanah}

Untuk pengujian sifat fisis Tanah Rawa (Lunak) Kelurahan Kastela terdiri dari pengujian kuat geser dan tekan bebas dengan hasil sebagai berikut :

\begin{tabular}{|c|c|c|c|c|c|c|c|}
\hline \multirow[t]{2}{*}{ NO } & \multirow{2}{*}{\multicolumn{2}{|c|}{$\begin{array}{c}\text { Macam } \\
\text { Pemeriksaan } \\
\text { tanah }\end{array}$}} & \multicolumn{5}{|c|}{ Hasil Pengujian } \\
\hline & & & $1 \%$ & $1,05 \%$ & $1,1 \%$ & $1,15 \%$ & $2 \%$ \\
\hline \multirow{3}{*}{1} & \multicolumn{2}{|c|}{ Kuat Geser } & & & & & \\
\hline & A & $\begin{array}{l}\text { Sudut } \\
\text { Gesek }\end{array}$ & $2,33^{\circ}$ & $6,40^{\circ}$ & $10,41^{\circ}$ & $15,27^{\circ}$ & $21,67^{\circ}$ \\
\hline & B & Kohesi & $\begin{array}{l}0,04 \\
\mathrm{~kg} / \mathrm{cm}^{2}\end{array}$ & $\begin{array}{l}0,01 \\
\mathrm{~kg} / \mathrm{cm}^{2}\end{array}$ & $\begin{array}{l}0,02 \\
\mathrm{~kg} / \mathrm{cm}^{2}\end{array}$ & $\begin{array}{l}0,03 \\
\mathrm{~kg} / \mathrm{cm}^{2}\end{array}$ & $\begin{array}{l}0,08 \\
\mathrm{~kg} / \mathrm{cm}^{2}\end{array}$ \\
\hline \multirow{3}{*}{2} & \multicolumn{2}{|c|}{ Tekan Bebas } & & & & & \\
\hline & A & qu & $\begin{array}{l}0,0122 \\
\mathrm{~kg} / \mathrm{cm}^{2}\end{array}$ & $\begin{array}{l}0,0124 \\
\mathrm{~kg} / \mathrm{cm}^{2}\end{array}$ & $\begin{array}{l}0,0128 \\
\mathrm{~kg} / \mathrm{cm}^{2}\end{array}$ & $\begin{array}{l}0,0136 \\
\mathrm{~kg} / \mathrm{cm}^{2}\end{array}$ & $\begin{array}{l}0,0702 \\
\mathrm{~kg} / \mathrm{cm}^{2}\end{array}$ \\
\hline & B & $\mathrm{Cu}$ & 0,0061 & 0,0062 & 0,0064 & 0,0068 & 0,0351 \\
\hline
\end{tabular}

\section{a. Pemeriksaan kuat geser tanah}

- Berdasarkan hasil pengujian kuat geser tanah dengan penambahan tanah $1 \%$ di bawah ini, maka nilai kuat geser yang diperoleh yaitu sebesar $2,33^{\circ}$ dan nilai kohesi sebesar $0,04 \mathrm{~kg} / \mathrm{cm}^{2}$.

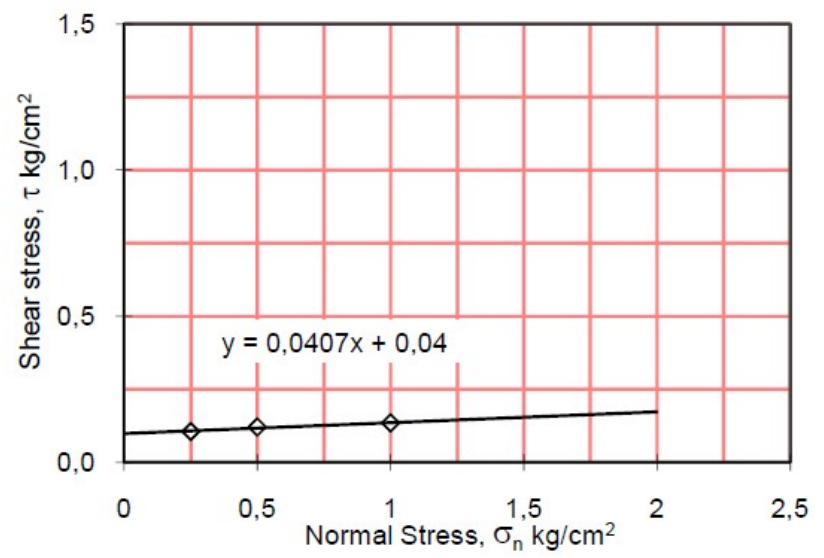

Gambar 3.1 Grafik hubungan tegangan geser dengan tegangan normal pada pengujian kuat geser dengan penambahan tanah $1 \%$.

- Berdasarkan hasil pengujian kuat geser tanah dengan penambahan tanah 1,05\% di bawah ini, maka nilai kuat geser yang di peroleh yaitu sebesar $6,40^{\circ}$ dan nilai kohesi sebesar $0,01 \mathrm{~kg} / \mathrm{cm} 2$. 


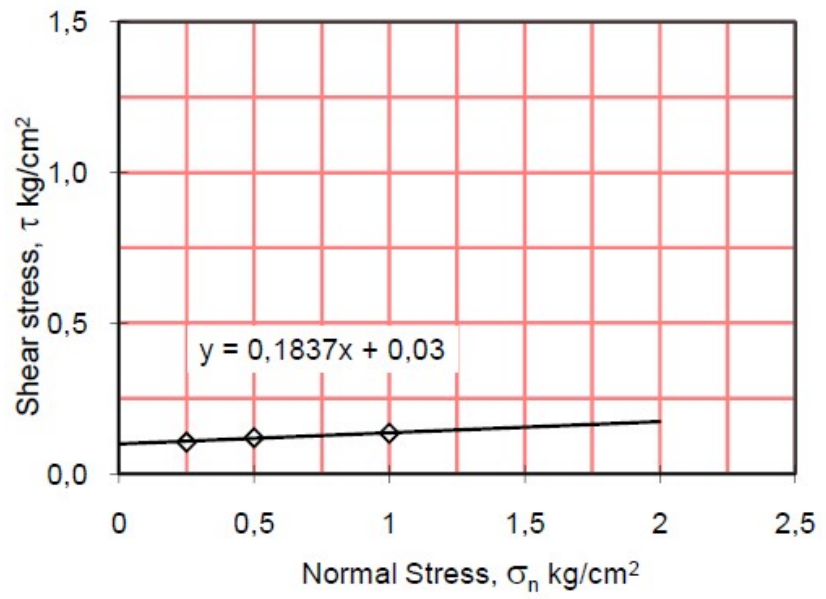

Gambar 3.2 Grafik hubungan tegangan geser dengan tegangan normal pada pengujian kuat geser tanah 1,05\%

- Berdasarkan hasil pengujian kut geser tanah dengan penambahan tanah 1,05\% di bawah ini, maka nilai kuat geser yang di peroleh yaitu sebesar $10,41^{\circ}$ dan nilai kohesi sebesar $0,02 \mathrm{~kg} / \mathrm{cm} 2$.

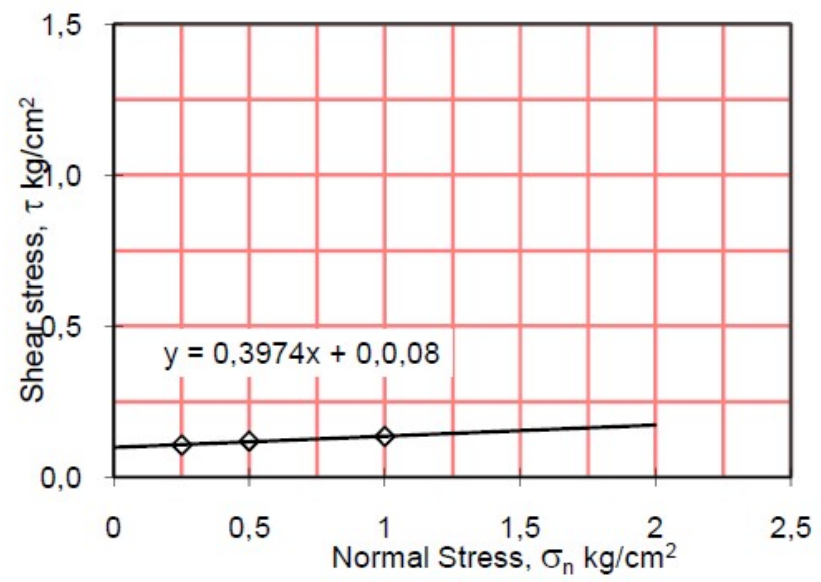

Gambar 3.3 Grafik hubungan tegangan geser dengan tegangan normal pada pengujian kuat geser tanah 1,1\%

- Berdasarkan hasil pengujian kuat geser tanah dengan penambahan tanah 1,15\% di bawah ini, maka nilai kuat geser yang diperoleh yaitu sebesar $15,27^{\circ}$ dan nilai kohesi sebesar $0,03 \mathrm{~kg} / \mathrm{cm} 2$. 


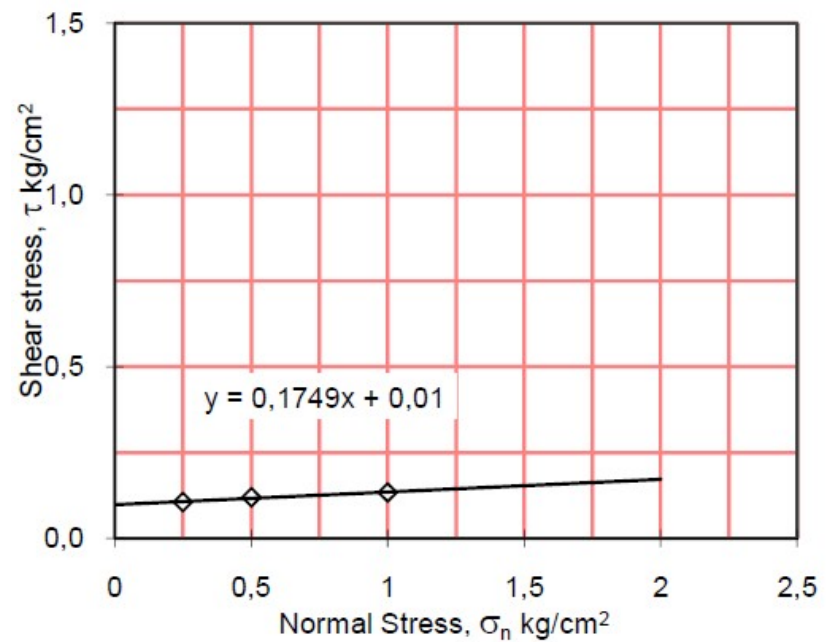

Gambar 3.4 Grafik hubungan tegangan geser dengan tegangan normal pada pengujian kuat geser tanah pada titik 1,15

- Berdasarkan hasil pengujian kuat geser tanah dengan penambahan tanah 1,15\% di atas di dapatkan niai kuat geser yaitu sebesar $15,27^{\circ}$ dan nilai kohesi sebesar $0,03 \mathrm{~kg} / \mathrm{cm}$.

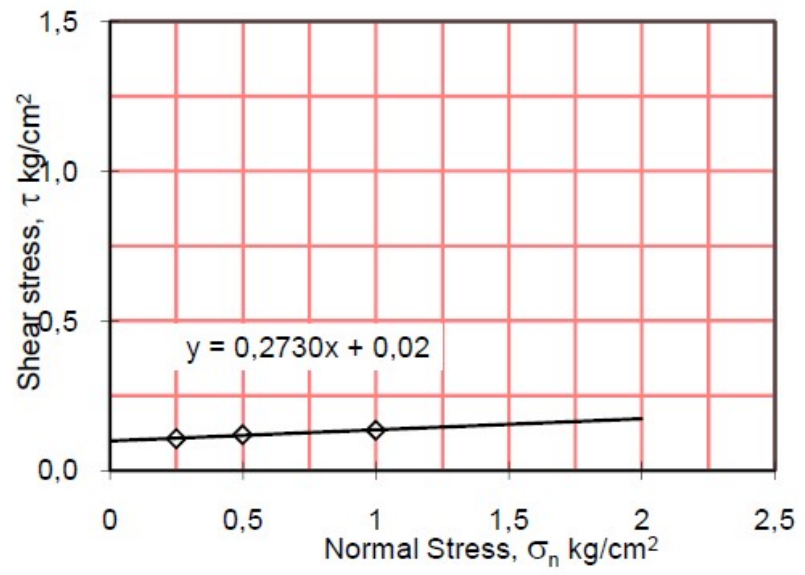

Gambar 3.5 Grafik hubungan tegangan geser dengan tegangan normal pada pengujian kuat geser tanah pada titik 2,0

\section{b. Pemeriksaan Kuat Tekan Bebas}

- Berdasarkan hasil pengujian kuat tekan bebas pada tanah asli dengan penambahan tanah 1,05\% di atas di dapatkan niai kuat tekan yaitu sebesar $0,0122 \mathrm{~kg} / \mathrm{cm}^{2}$

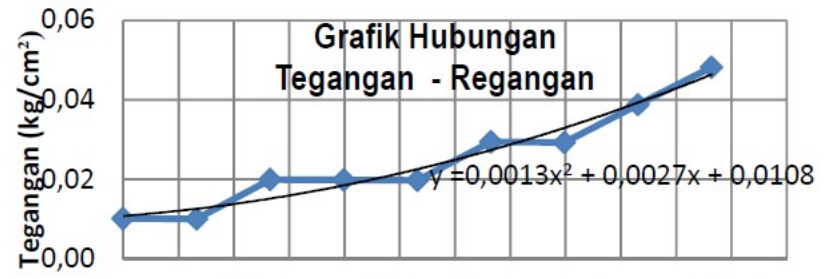

$\begin{array}{llllllllllllll}0,0 & 0,4 & 0,8 & 1,2 & 1,6 & 2,0 & 2,4 & 2,8 & 3,2 & 3,6 & 4,0 & 4,4 & 4,8\end{array}$

Regangan (\%)

Gambar 3.6 Grafik hubungan tegangan dengan regangan pada pengujian tanah 1\%

- Berdasarkan hasil pengujian kuat tekan bebas pada tanah asli dengan penambahan tanah 1,05\% di atas di dapatkan niai kuat tekan yaitu sebesar $0,0124 \mathrm{~kg} / \mathrm{cm}^{2}$. 


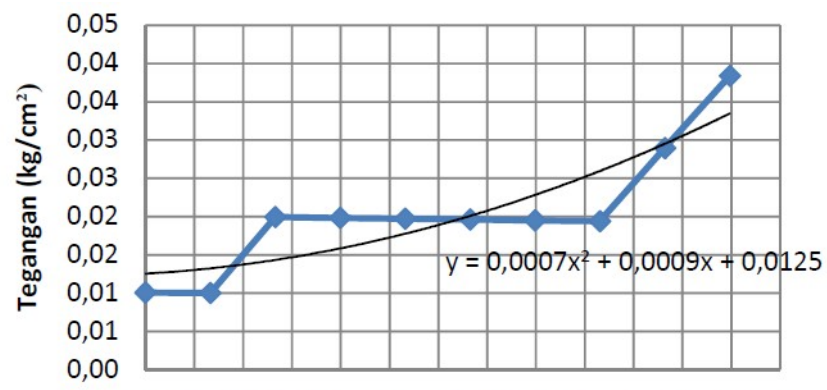

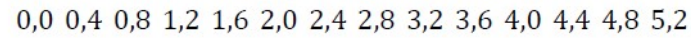

Regangan (\%)

Gambar 3.7 Grafik hubungan tegangan dengan regangan pada pengujian tanah 1,05\%

- Berdasarkan hasil pengujian kuat tekan bebas pada tanah asli dengan penambahan tanah 1,1\% di atas di dapatkan niai kuat tekan yaitu sebesar $0,0128 \mathrm{~kg} / \mathrm{cm}^{2}$

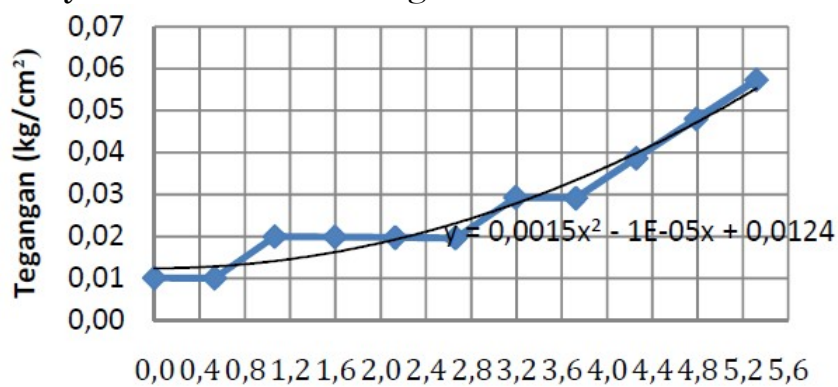

Regangan (\%)

Gambar 3.8 Grafik hubungan tegangan dengan regangan pada pengujian tanah 1,1\%

- Berdasarkan hasil pengujian kuat tekan bebas pada tanah asli dengan penambahan tanah 1,15\% di atas di dapatkan niai kuat tekan yaitu sebesar $0,0136 \mathrm{~kg} / \mathrm{cm}^{2}$.

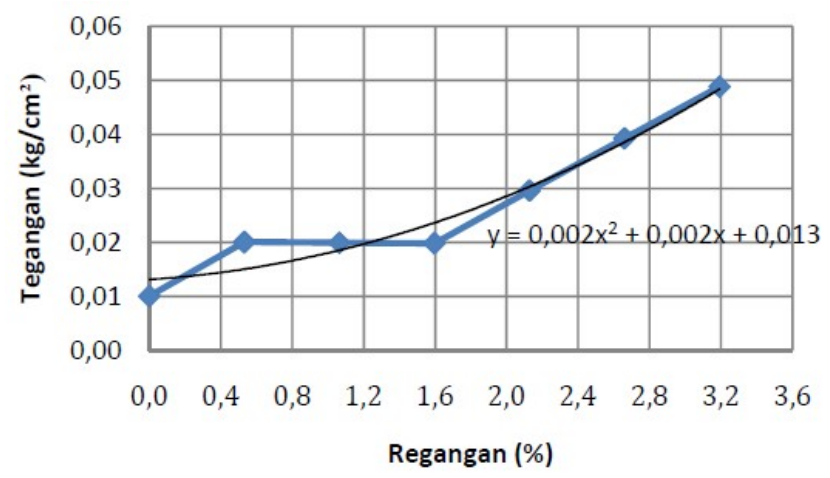

Gambar 3.9 Grafik hubungan tegangan dengan regangan pada pengujian tanah 1,15\%

- Berdasarkan hasil pengujian kuat tekan bebas pada tanah asli dengan penambahan tanah 2,0\% di atas di dapatkan niai kuat tekan yaitu sebesar $0,0702 \mathrm{~kg} / \mathrm{cm}^{2}$ 


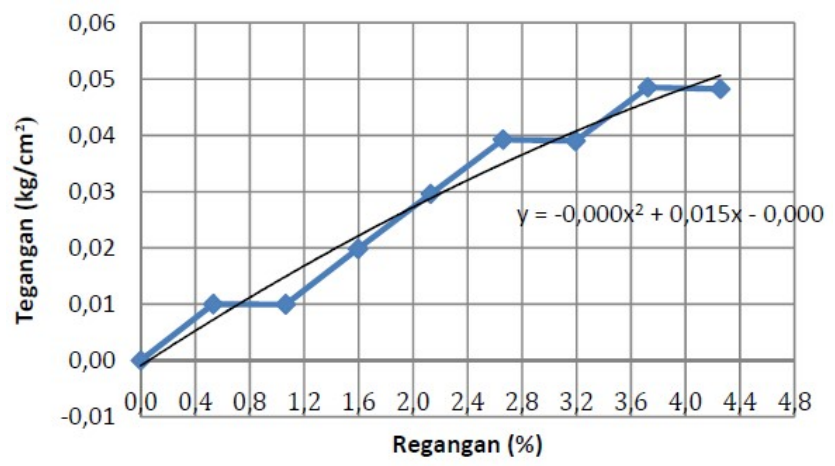

Gambar 3.10 Grafik hubungan tegangan dengan regangan pada pengujian tanah $2 \%$

\section{Daftar Pustaka}

[1] Peraturan Pemerintah Republik indonesia Nomor. 27 Tahun 1991 tentang rawa

[2] Peraturan Pemerintah Republik indonesia Nomor. 73 Tahun 2013 tentang rawa

$[3]$

Das, Braja M. 1955 Mekanika Tanah (Prinsip-Prinsip Rekayasa Geoteknis). Jilid 1. Jakarta Erlangga

Alif Noor. (2004) Permintakatan Daerah yang Rawan Pencemaran Air Tanah Sebagai Dasar Perencanaan Penyediaan Air Bersih di Surakarta. Jurnal forum GeografiVolume 18 No 2004. Surakarta Fakultas Geografi, Universitas Muhamadiyah Surakarta.

[5] ASTM D-1556 (Standard Test Method for Density and Unit Weight of Soil in Place by the Sand-Cone Method) tentang rawa Nomor. 73 tahun 2013

[6] Dini Anita Saragi. 2014, Skripsi teknik perbaikan tanah lunak sebagai lapisan tanah dasar (subgrade) G. Perangin-angin Jurnal Sipil dan Perencanaan, Vol. 13 No. 2, Agustus 2009Studi Potensi Tanah Timbunan Sebagai Material Konstruksi Tanggul Pada Ruas Jalan Negara Liwa Ranau di Kabupaten Lampung Barat

[7] Hardiyatmo, H.C., 2002, Stabilisasi Tanah untuk Perkerasan Jalan. Universitas Gajah Mada.

[8] Hary Christady Hardiatmo 2002, Mekanika Tanah 1 GADJAH MADA UNIVERSITY PREES

[9] SNI 03-2828-1992 (Metoda Pengujian Kepadatan Lapangan dengan Alat Konus Pasir)

[10] Standar AASHTO untuk pengujian sand cone adalah : AASHTO T-191 (Density of Soil In-Place by the Sand-Cone Method)

[11] Subagyo H. 2007 Karateristik Dan Pengolahan Lahan Rawa (Lahan Pasang Surut Rawa) Balai besar penelitian dan pengembangan sumber daya lahan pertanian bogor. 